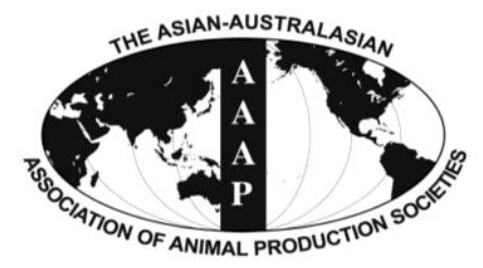

Asian-Aust. J. Anim. Sci.

Vol. 25, No. 2 : 272 - 277

February 2012

www.ajas.info

http://dx.doi.org/10.5713/ajas.2011.11098

\title{
Compensatory Growth of Grower Olive Flounder (Paralichthys olivaceus) with Different Feeding Regime at Suboptimal Temperature
}

\author{
S. H. Cho*, K. T. Kim, I. C. Choi, G. H. Jeon and D. S. Kim ${ }^{1}$ \\ Division of Marine Environment and BioScience, College of Ocean Science and Technology, \\ Korea Maritime University, Busan 606-791, Korea
}

\begin{abstract}
Compensatory growth of grower olive flounder (Paralichthys olivaceus) was determined at suboptimal temperature $\left(13.0 \pm 1.9^{\circ} \mathrm{C}\right)$. Fifteen fish averaging $201.1 \mathrm{~g}$ per tank were distributed into 18 of $300 \mathrm{~L}$ flow-through tanks. Six treatments were prepared in triplicate: fish were hand-fed with an extruded pellet to apparent satiation once a day for 16 weeks (16 WF); and the other five groups of fish were hand-fed for 15, 14, 13, 12 and 10 weeks after 1-, 2-, 3-, 4- and 6-week feed deprivation, referred to as 15 WF, 14 WF, 13 $\mathrm{WF}, 12 \mathrm{WF}$ and $10 \mathrm{WF}$, respectively. A linear relationship between body weight of fish and feed deprivation was observed: Y (Body weight of fish) $=-1.81 \mathrm{X}$ (Weeks of feed deprivation) $+201.07, \mathrm{R}^{2}=0.83$. Weight gain of grower olive flounder in $15 \mathrm{WF}, 14 \mathrm{WF}, 13 \mathrm{WF}$ and $12 \mathrm{WF}$ treatments was comparable to that of fish in $16 \mathrm{WF}$ treatment, but lower than that of fish in $10 \mathrm{WF}$ treatment. Specific growth rate of fish in $15 \mathrm{WF}$ treatment was higher than that of fish in $16 \mathrm{WF}, 14 \mathrm{WF}$ and $10 \mathrm{WF}$ treatments. Feed consumption of fish was not affected by feeding regime. Feed and protein efficiency ratios of fish in 15 WF treatment were higher than those of fish in 13 WF, $12 \mathrm{WF}$ and $10 \mathrm{WF}$ treatments. Grower olive flounder could achieve full compensatory growth when fish were daily fed for 12 weeks after 4-week feed deprivation at suboptimal temperature. (Key Words : Olive Flounder (Paralichthys olivaceus), Compensatory Growth, Grower, Feed Deprivation, Suboptimal Temperature)
\end{abstract}

\section{INTRODUCTION}

Olive flounder (Paralichthys olivaceus) is one of the most commercially important marine fish species for aquaculture in Eastern Asia including Korea, Japan and China, and its optimum temperature conditions was known to range $20-25^{\circ} \mathrm{C}$ (Iwata et al., 1994). However, water temperature can rise above $30^{\circ} \mathrm{C}$ in the summer and fall below $10^{\circ} \mathrm{C}$ in the winter in wild. Therefore, this fish species seems to tolerate a wide range of temperature.

Compensatory growth of fish is rapid or faster than normal growth rate of fish resulting from refeeding after fasting. Achieving compensatory growth of fish can have the several advantages for aquaculture such as saving feed and labor costs, reducing water pollution during starvation, and improving feeding activity and feed efficiency shortly after refeeding. Huang et al. (2008) reported that juvenile

\footnotetext{
* Corresponding Author : S. H. Cho. Tel: +82-51-410-4755, Fax: +82-51-404-4750, E-mail: chosunh@hhu.ac.kr

${ }^{1}$ Department of Marine Bio-Materials and Aquaculture, Pukyong National University, Busan 608-739, Korea.

Received April 11, 2011; Accepted August 4, 2011
}

olive flounder averaging $12 \mathrm{~g}$ subjected to low temperature of $8.5^{\circ} \mathrm{C}$ for 10 days and followed by being grown at an optimum temperature of $22^{\circ} \mathrm{C}$ for the next 30 days achieved full compensatory growth. In addition, juvenile olive flounder averaging $53.9 \mathrm{~g}$ and $16 \mathrm{~g}$ achieved full compensatory growth after the 2 -week feed deprivation at mean temperatures of $15^{\circ} \mathrm{C}$ and $23.6^{\circ} \mathrm{C}$ in the 8 -week trials (Cho, 2005; Cho et al., 2006).

However, compensatory growth responses could vary depending on several factors such as fish species (Jobling et al., 1994; Wang et al., 2000), fish size (Bilton and Robins, 1973), dietary nutrient composition (Cho and Heo, 2010), duration of feeding trial (Rueda et al., 1998; Heide et al., 2006), feeding regime (Chatakondi and Yant, 2001; Zhu et al., 2004; Oh et al., 2007; Cho and Cho, 2009) and social factors (Jobling and Koskela, 1996; Hayward et al., 1997, 2000). Furthermore, Ali et al. (2003) indicated that partial, full and overcompensation could be evoked in fish although overcompensation had only been observed when cycles of deprivation and satiation feeding had been imposed.

Generally speaking, grower olive flounder must overwinter to grow up to highly valuable marketing size at 
fish farm. To date, there have been only few studies with grower olive flounder (Kim et al., 2009) compared to studies with juvenile fish (Iwata et al., 1994; Cho, 2005; Huang et al., 2008; Cho and Heo, 2010). In addition, no study on compensatory growth of grower olive flounder has been performed yet. In this study, therefore, compensatory growth of grower olive flounder with different feeding regime was determined at suboptimal temperature.

\section{MATERIALS AND METHODS}

\section{Fish and the experimental conditions}

Grower (ca. $200 \mathrm{~g}$ ) olive flounder were purchased from a private farm and acclimated to the experimental conditions for 4 weeks. During the acclimation period, fish were fed with the commercial extruded pellet (EP) once a day as much as they voluntarily eat which was about 0.2 $0.5 \%$ total biomass. Fifteen fish (an initial body weight of fish: $201.1 \pm 0.2 \mathrm{~g}$ ) per tank were randomly chosen and distributed into 18 of $300 \mathrm{~L}$ flow-through tanks (water volume $250 \mathrm{~L}$ ). The water source was the sand-filtered natural seawater and aeration supplied to each tank. The flow rate of water into each tank was $8.6 \mathrm{~L} / \mathrm{min}$. Water temperature ranged from $9.8^{\circ} \mathrm{C}$ to $16.5^{\circ} \mathrm{C}$ (mean $\pm \mathrm{SD}$ : $13.0 \pm 1.9^{\circ} \mathrm{C}$ ) and photoperiod left natural condition.

\section{Design of the feeding trial}

Six treatments were prepared in triplicate: fish were hand-fed with the EP (Suhyup Feed Co. Ltd., Korea) containing $51.6 \%$ crude protein and $14.9 \%$ crude lipid to apparent satiation once a day (09:00), seven days a week, for 16 week (16 WF), which was used as a control group; and five other groups of fish were hand-fed with the EP to apparent satiation once a day for 15, 14, 13, 12 and 10 weeks after 1-, 2-, 3-, 4- and 6-week feed deprivation, referred to as $15 \mathrm{WF}, 14 \mathrm{WF}, 13 \mathrm{WF}, 12 \mathrm{WF}$ and $10 \mathrm{WF}$, respectively. Fish from each tank were weighed to measure reduction in body weight of fish a day before feeding according to designated feeding schedule. At the end of 16week trial, fish from each tank were weighed after being starved for a day.

\section{Growth parameters}

Following final weighing five fish from each tank were sampled. Total fish length ( $\mathrm{mm})$ and fish weight $(\mathrm{g})$ calculated by the weight of biomass in tank divided by number of fish was measured. Liver was obtained from samples and weighed. Following indices were calculated; $\mathrm{CF}=$ body weight $(\mathrm{g}) /$ total length $(\mathrm{cm})^{3}$ and HSI $=$ liver weight/body weight. Other criteria measured were as follows; specific growth rate $(\mathrm{SGR})=(\mathrm{Ln}$ final weight of fish-Ln initial weight of fish) $\times 100$ /days of feeding trial, feed consumption $(\mathrm{g} / \mathrm{fish})=$ total feed consumption/number of fish, feed efficiency ratio $($ FER $)=$ weight gain of fish/feed consumed and protein efficiency ratio (PER) = weight gain of fish/protein consumed.

\section{Analysis of proximate composition}

Three fish at the beginning and from each tank at the end of the study were sampled for proximate analysis. Fish were dissected and the whole body excluding the liver and liver of fish were separated. The whole body of fish excluding liver and the liver were separately homogenized before proximate analysis. Crude protein content determined using Kjeldahl method (Kjeltec 2100 Distillation Unit, Foss Tecator, Hoganas, Sweden), lipid content determined using ether-extraction method, moisture content determined by drying sample in a dry oven at $105^{\circ} \mathrm{C}$ for $24 \mathrm{~h}$, fiber content determined using automatic analyzer (Fibertec, Tecator, Hoganas, Sweden) and ash content determined using muffle furnace at $550^{\circ} \mathrm{C}$ for $4 \mathrm{~h}$, all methods were according to standard AOAC (1990).

\section{Statistical analysis}

One-way ANOVA and least significant difference (Fisher's LSD) test were used to analyze the significance $(p<0.05)$ of the difference among the means of treatments. Regression analysis for weight loss of olive flounder during starvation was conducted using SAS Version 9.1 (SAS Institute, Cary, NC, USA). All percentage data were transformed to arcsine values prior to analysis.

\section{RESULTS AND DISCUSSION}

A linear relationship between body weight of grower olive flounder (Y) and weeks of feed deprivation (X) was observed: $\mathrm{Y}=-1.81 \mathrm{X}+201.07, \mathrm{R}^{2}=0.83$ (Figure 1). A higher negative slope $(-1.81)$ relationship between body weight of grower olive flounder and weeks of feed deprivation indicates that a greater weight loss per week of feed deprivation than that observed in juvenile olive flounder (slope $=-0.81$ at $15^{\circ} \mathrm{C}$ and slope $=-0.57$ at $23.6^{\circ} \mathrm{C}$ (Cho, 2005; Cho et al., 2006), agreeing with Adelman et al. (1955)'s study showing that larger brook trout (Salvelinus fontinalis) lost more body weight than smaller fish when starved for 6 months.

Survival over the 16 week experimental period ranged from $91 \%$ to $100 \%$ was not significantly $(p>0.1)$ different among treatments (Table 1). However, weight gain of grower olive flounder in $15 \mathrm{WF}, 14 \mathrm{WF}, 13 \mathrm{WF}$ and $12 \mathrm{WF}$ treatments was comparable to that of fish in $16 \mathrm{WF}$ treatment, but significantly $(\mathrm{p}<0.02)$ lower than that of fish in $10 \mathrm{WF}$ treatment. This indicated that grower olive flounder could achieve full compensatory growth after 4week feed deprivation at suboptimal temperature in this study. Similarly, channel catfish (averaging $22 \mathrm{~g}$ and $420 \mathrm{~g}$ ) partially fed achieved same weight gain as fish continuously fed when fish were continuously fed, partially or non-fed 


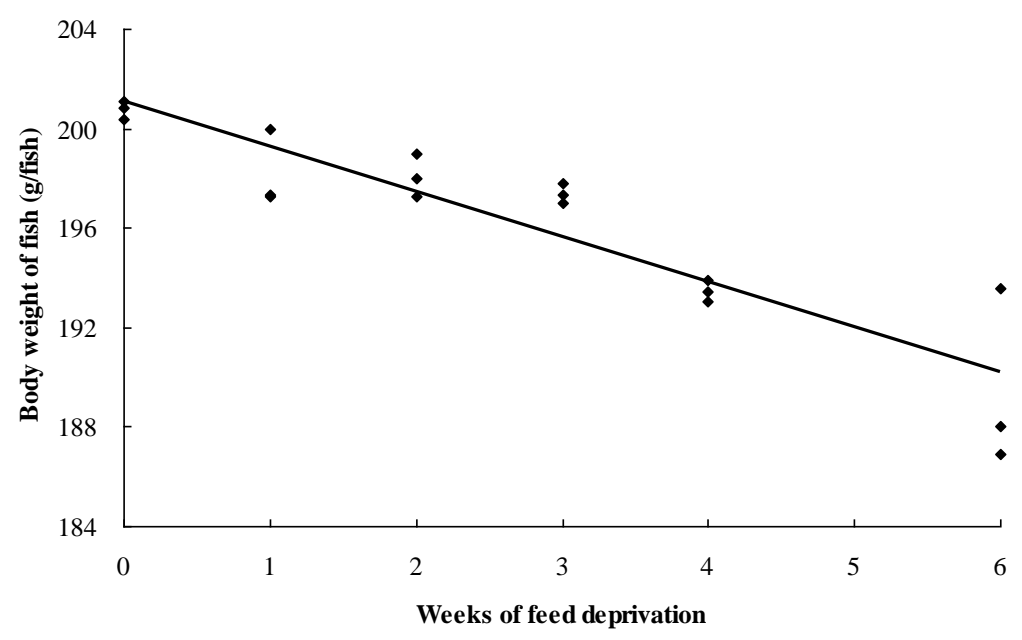

Figure 1. Change in body weight $(\mathrm{g} / \mathrm{fish})$ of grower olive flounder with weeks of feed deprivation $(\mathrm{n}=3)$ : $\mathrm{Y}($ Body weight of fish $)=$ $-1.81 \mathrm{X}$ (Weeks of feed deprivation) $+201.07, \mathrm{R}^{2}=0.83$ ).

throughout the overwintering period from December to April at earthen ponds (Kim and Lovell, 1995). When juvenile olive flounder were subjected to a range of temperature treatments $\left(8.5,13.0,17.5,22.0\right.$ and $\left.26.5^{\circ} \mathrm{C}\right)$ for 10 days, even the fish held at $8.5^{\circ} \mathrm{C}$ achieved full compensation when subsequently reared at $22.0^{\circ} \mathrm{C}$ for 30 days (Huang et al., 2008). The results of Cho (2005), Cho et al. (2006) and Huang et al. (2008) and the present study probably indicated that eurythermal fish like the olive flounder could display compensatory growth over a range of temperatures.

The mean daily specific growth rate (SGR) in the $15 \mathrm{WF}$ treatment was significantly $(\mathrm{p}<0.01)$ higher than that of fish in $16 \mathrm{WF}, 14 \mathrm{WF}$ and $10 \mathrm{WF}$ treatments, but not significantly $(p>0.05)$ different from that of fish in $13 \mathrm{WF}$ and $12 \mathrm{WF}$ treatments in this study. The mean daily SGR of fish in $15 \mathrm{WF}, 14 \mathrm{WF}, 13 \mathrm{WF}$ and $12 \mathrm{WF}$ treatments was also higher than that of fish in $10 \mathrm{WF}$ treatment. Oliver flounder over 150-200 $\mathrm{g}$ are usually fed to satiation no more than once a day at fish farm for easy management and cost effective production. Since the daily mean SGR $(0.16 \% / d)$ of grower olive flounder in this study was comparable to that $(0.20 \% / \mathrm{d})$ of fish grown from 270 to $350 \mathrm{~g}$ in Kim et al. (2009)'s study, in which fish were fed with the commercial EP $(52.3 \%$ crude protein and 12.8 crude lipid) to satiation once a day at mean temperature of $12^{\circ} \mathrm{C}$ for 15 weeks, growth of fish seemed to be well achieved in this study. Recently, Kim et al. (2010) showed that SGR of grower olive flounder averaging $255 \mathrm{~g}$ ranged $0.18-0.56 \% / \mathrm{d}$ when fish were fed with the diets containing various protein (40, 45 and 50\%) and lipid (7 and 14\%) levels to satiation twice a day at $15.5^{\circ} \mathrm{C}$ for 14 weeks. In addition, Iwata et al. (1994) reported SGR values of 0.18 and $0.71 \% / \mathrm{d}$ for olive flounder averaging $176 \mathrm{~g}$ when fish were fed with the commercial diet ( $60 \%$ crude protein and $14 \%$ crude lipid) to satiation twice a day at 10 and $15^{\circ} \mathrm{C}$ for 35 days, respectively.

Feed consumption (g/fish) of grower olive flounder was not significantly ( $\mathrm{p}>0.08)$ affected by feeding regime (Table 2 ). No difference in feed consumption of fish in this study probably supported full compensatory growth of fish. This agreed with other studies (Rueda et al., 1998; Gaylord and Gatlin, 2000; Wang et al., 2000; Tian and Qin, 2004; Cho, 2005; Cho et al., 2006; Oh et al., 2007) showing that

Table 1. Survival (\%), weight gain (g/fish) and specific growth rate (SGR) of grower olive flounder fed the extruded pellet with different feeding regime for 16 weeks

\begin{tabular}{lccccc}
\hline Treatments & $\begin{array}{c}\text { Initial weight of fish } \\
\text { (g/fish) }\end{array}$ & $\begin{array}{c}\text { Final weight of fish } \\
(\mathrm{g} / \mathrm{fish})\end{array}$ & $\begin{array}{c}\text { Survival } \\
(\%)\end{array}$ & $\begin{array}{c}\text { Weight gain } \\
(\mathrm{g} / \mathrm{fish})\end{array}$ & $\begin{array}{c}\text { SGR }^{1} \\
(\% / \mathrm{d})\end{array}$ \\
\hline $16 \mathrm{WF}$ & $200.78 \pm 0.21$ & $239.83 \pm 4.23$ & $97.78 \pm 2.22$ & $39.05 \pm 4.30^{\mathrm{a}}$ & $0.16 \pm 0.02^{\mathrm{bc}}$ \\
$15 \mathrm{WF}$ & $201.09 \pm 0.18$ & $275.38 \pm 15.71$ & $91.11 \pm 4.44$ & $74.30 \pm 15.53^{\mathrm{a}}$ & $0.28 \pm 0.05^{\mathrm{a}}$ \\
$14 \mathrm{WF}$ & $201.36 \pm 0.21$ & $247.80 \pm 11.04$ & $100.00 \pm 0.00$ & $46.44 \pm 10.83^{\mathrm{a}}$ & $0.18 \pm 0.04^{\mathrm{b}}$ \\
$13 \mathrm{WF}$ & $201.36 \pm 0.23$ & $247.69 \pm 10.26$ & $100.00 \pm 0.00$ & $46.33 \pm 10.25^{\mathrm{a}}$ & $0.18 \pm 0.04^{\mathrm{ab}}$ \\
$12 \mathrm{WF}$ & $201.29 \pm 0.12$ & $254.56 \pm 2.89$ & $100.00 \pm 0.00$ & $53.27 \pm 3.00^{\mathrm{a}}$ & $0.21 \pm 0.01^{\mathrm{ab}}$ \\
$10 \mathrm{WF}$ & $201.04 \pm 0.27$ & $218.56 \pm 2.21$ & $95.56 \pm 2.22$ & $17.52 \pm 2.26^{\mathrm{b}}$ & $0.07 \pm 0.01^{\mathrm{c}}$ \\
\hline
\end{tabular}

Values (mean of triplicate \pm SE) in the same column sharing a common superscript are not significantly different ( $p>0.05$ ).

${ }^{1}$ Specific growth rate $($ SGR, \%/d) $=100 \times((\operatorname{Ln}$ final weight of fish-Ln initial weight of fish $) /$ days of trial $)$. 
Table 2. Feed consumption (g/fish), feed efficiency ratio (FER), protein efficiency ratio (PER), condition factor (CF) and hepatosomatic index (HSI) of grower olive flounder fed the extruded pellet with different feeding regime for 16 weeks

\begin{tabular}{lccccc}
\hline Treatments & Feed consumption & FER $^{1}$ & PER $^{2}$ & CF $^{3}$ & HSI $^{4}$ \\
\hline $16 \mathrm{WF}$ & $47.29 \pm 3.47$ & $0.82 \pm 0.04^{\mathrm{ab}}$ & $1.59 \pm 0.08^{\mathrm{ab}}$ & $1.01 \pm 0.04$ & $1.46 \pm 0.13$ \\
$15 \mathrm{WF}$ & $81.14 \pm 17.79$ & $0.92 \pm 0.02^{\mathrm{a}}$ & $1.78 \pm 0.14^{\mathrm{a}}$ & $0.98 \pm 0.03$ & $1.76 \pm 0.03$ \\
$14 \mathrm{WF}$ & $64.27 \pm 15.44$ & $0.74 \pm 0.10^{\mathrm{abc}}$ & $1.43 \pm 0.20^{\mathrm{abc}}$ & $0.97 \pm 0.11$ & $1.46 \pm 0.17$ \\
$13 \mathrm{WF}$ & $63.38 \pm 7.43$ & $0.72 \pm 0.07^{\mathrm{bc}}$ & $1.39 \pm 0.14^{\mathrm{bc}}$ & $1.09 \pm 0.09$ & $1.52 \pm 0.17$ \\
$12 \mathrm{WF}$ & $91.39 \pm 9.99$ & $0.60 \pm 0.07^{\mathrm{c}}$ & $1.16 \pm 0.14^{\mathrm{c}}$ & $1.13 \pm 0.11$ & $1.71 \pm 0.03$ \\
$10 \mathrm{WF}$ & $46.66 \pm 6.03$ & $0.38 \pm 0.03^{\mathrm{d}}$ & $0.73 \pm 0.06^{\mathrm{d}}$ & $0.98 \pm 0.05$ & $1.68 \pm 0.18$ \\
\hline
\end{tabular}

Values (mean of triplicate $\pm \mathrm{SE}$ ) in the same column sharing a common superscript are not significantly different ( $>0.05)$.

${ }^{1}$ Feed efficiency ratio $($ FER $)=$ Weight gain of fish/feed consumed. ${ }^{2}$ Protein efficiency ratio $(\mathrm{PER})=$ Weight gain of fish/protein consumed .

${ }^{3}$ Condition factor $(\mathrm{CF})=$ Body weight $(\mathrm{g}) /$ total length $(\mathrm{cm})^{3} .{ }^{4}$ Hepatosomatic index $(\mathrm{HSI})=$ Liver weight $(\mathrm{g}) /$ body weight $(\mathrm{g})$.

hyperphagia was observed in fish achieving full compensatory growth. Although feed consumption of olive flounder in $10 \mathrm{WF}$ treatment was almost same as in $16 \mathrm{WF}$ treatment, lower weight gain of fish was observed in the latter.

However, feed and protein efficiency ratios of fish in 15 WF treatment were significantly $(p<0.001)$ higher than those of fish in $13 \mathrm{WF}, 12 \mathrm{WF}$ and $10 \mathrm{WF}$ treatments, but not significantly $(p>0.05)$ different from those of fish in $16 \mathrm{WF}$ and $14 \mathrm{WF}$ treatments in this study. Feed and protein efficiency ratios of fish in $16 \mathrm{WF}, 14 \mathrm{WF}, 13 \mathrm{WF}$ and 12 WF treatments were also higher than those of fish in $10 \mathrm{WF}$ treatment, which was lowest. Higher feed and protein efficiency ratios of fish in $16 \mathrm{WF}, 15 \mathrm{WF}, 14 \mathrm{WF}, 13 \mathrm{WF}$ and $12 \mathrm{WF}$ treatments compared to those of fish in $10 \mathrm{WF}$ treatment partially agreed with other studies (Jobling et al., 1994; Gaylord and Gatlin, 2000, 2001; Cho, 2005; Oh et al., 2007; Cho and Heo, 2010) showing that improvement in feed utilization was observed in fish achieving compensatory growth.

Neither CF $(p>0.8)$ nor HSI $(p>0.5)$ of grower olive flounder was different among treatments in this study. Unlike this study, however, HSI was a good index to indicate compensatory growth of channel catfish and olive flounder (Gaylord and Gatlin, 2000; Cho, 2005). In addition, Miglavs and Jobling (1989) showed that the relative sizes of liver and viscera decreased with either feed deprivation for 16 weeks or restricted feeding, which was $10 \%$ of feed consumption at satiation feeding for 8 weeks in Arctic charr (Salvelinus aplinus) and increased to levels exceeding those of fish fed continuously to satiation after fish were transferred from restricted to satiation feeding for the following 8 weeks.

Moisture $(p>0.7)$, crude lipid $(p>0.1)$ and ash $(p>0.8)$ content of the whole body excluding liver and moisture $(\mathrm{p}>0.9)$ and crude lipid $(\mathrm{p}>0.1)$ content of liver of grower olive flounder was not significantly affected by feeding regime (Table 3). However, crude protein content of the

Table 3. Chemical composition (\%, wet weight) of the whole body excluding liver and liver of grower olive flounder at the end of the 16-week feeding trial

\begin{tabular}{|c|c|c|c|c|}
\hline \multirow{2}{*}{ Treatments } & \multicolumn{4}{|c|}{ Whole body excluding liver } \\
\hline & Moisture & Crude protein & Crude lipid & Ash \\
\hline $16 \mathrm{WF}$ & $72.53 \pm 0.27$ & $18.13 \pm 0.38^{\mathrm{ab}}$ & $4.50 \pm 0.49$ & $3.63 \pm 0.19$ \\
\hline $15 \mathrm{WF}$ & $72.17 \pm 0.46$ & $17.53 \pm 0.43^{\mathrm{bc}}$ & $3.93 \pm 0.54$ & $3.47 \pm 0.03$ \\
\hline $14 \mathrm{WF}$ & $73.80 \pm 1.55$ & $17.57 \pm 0.12^{\mathrm{bc}}$ & $4.40 \pm 0.15$ & $3.70 \pm 0.46$ \\
\hline $13 \mathrm{WF}$ & $73.33 \pm 1.24$ & $17.03 \pm 0.29^{c}$ & $3.17 \pm 0.55$ & $3.73 \pm 0.15$ \\
\hline $12 \mathrm{WF}$ & $72.83 \pm 1.73$ & $18.90 \pm 0.44^{\mathrm{a}}$ & $4.90 \pm 0.64$ & $3.47 \pm 0.09$ \\
\hline \multirow[t]{3}{*}{$10 \mathrm{WF}$} & $74.20 \pm 0.60$ & $17.17 \pm 0.07^{\mathrm{bc}}$ & $3.33 \pm 0.17$ & $3.43 \pm 0.12$ \\
\hline & \multicolumn{4}{|c|}{ Liver } \\
\hline & Moisture & \multicolumn{2}{|c|}{ Crude protein } & Crude lipid \\
\hline $16 \mathrm{WF}$ & $67.33 \pm 2.63$ & \multicolumn{2}{|c|}{$12.60 \pm 0.21^{\mathrm{b}}$} & $15.90 \pm 0.50$ \\
\hline $15 \mathrm{WF}$ & $67.27 \pm 0.63$ & \multicolumn{2}{|c|}{$13.50 \pm 0.00^{\mathrm{a}}$} & $15.37 \pm 0.09$ \\
\hline $14 \mathrm{WF}$ & $68.43 \pm 1.39$ & \multicolumn{2}{|c|}{$11.73 \pm 0.34^{\mathrm{c}}$} & $15.47 \pm 0.49$ \\
\hline $13 \mathrm{WF}$ & $68.17 \pm 1.81$ & \multicolumn{2}{|c|}{$12.43 \pm 0.20^{\mathrm{bc}}$} & $15.43 \pm 0.82$ \\
\hline $12 \mathrm{WF}$ & $67.23 \pm 2.40$ & \multicolumn{2}{|c|}{$12.87 \pm 0.15^{\mathrm{ab}}$} & $15.43 \pm 1.48$ \\
\hline $10 \mathrm{WF}$ & $69.53 \pm 0.92$ & \multicolumn{2}{|c|}{$10.87 \pm 0.33^{\mathrm{d}}$} & $12.63 \pm 0.69$ \\
\hline
\end{tabular}

Values (mean of triplicate \pm SE) in the same column sharing a common superscript are not significantly different ( $p>0.05$ ). 
whole body excluding liver of fish in the $12 \mathrm{WF}$ treatment was significantly $(\mathrm{p}<0.01)$ higher than for fish in the other treatments with the exception of the $16 \mathrm{WF}$ treatment. In addition, crude protein content of the whole body excluding liver for fish in the $16 \mathrm{WF}$ treatment was also higher than for fish in the $13 \mathrm{WF}$ treatment, which had the lowest level. Crude protein content of liver of fish in $15 \mathrm{WF}$ treatment was significantly $(p<0.0001)$ higher than that of liver of fish in all other treatments except for that of the liver of fish in $12 \mathrm{WF}$ treatment. In addition, crude protein content of liver of fish in $16 \mathrm{WF}, 14 \mathrm{WF}$ and $13 \mathrm{WF}$ treatments was also higher than that of liver of fish in $10 \mathrm{WF}$ treatment, which was lowest.

When rainbow trout (Oncorhynchus mykiss) and gibel carp (Carassius auratus gibelio) were starved for a defined period of time, body fat decreased, but body moisture and protein increased compared to fish without feed deprivation; however, the fish restored the body fat shortly after satiation feeding (Quinton and Blake, 1990; Xie et al., 2001). This resulted to no difference in body proximate composition of fish with different feeding regimes at the end of the feeding trials (Gaylord and Gatlin, 2000; Xie et al., 2001; Zhu et al., 2004; Cho et al., 2006). Miglavs and Jobling (1989) reported that lipid decreased and water increased in the eviscerated carcass of Arctic charr with feed deprivation; however, liver lipid content of restrictedsatiation fish followed by satiation feeding was higher than that of fish fed to satiation without feed deprivation in 16week feeding trial.

In conclusion, grower olive flounder could achieve full compensatory growth up to 4-week feed deprivation when fish were fed with extruded pellet to apparent satiation once a day for 16 weeks or $15,14,13,12$ and 10 weeks after 1-, 2-, 3-, 4- and 6-week feed deprivation at suboptimal temperature.

\section{ACKNOWLEDGMENTS}

This research was a part of the project titled "Development of Technologies for Risk Assessment of Marine Living Genetically Modified Organisms" funded by the Ministry of Land, Transport and Maritime Affairs, Korea.

\section{REFERENCES}

Ali, M., A. Nicieza and R. J. Wootton. 2003. Compensatory growth in fishes: a response to growth depression. Fish Fish. 4:147-190.

AOAC. 1990. Official methods of analysis. 15th edn. Association of Official Analytical Chemists, Arlington, Virginia, USA.

Adelman, H. M., J. L. Bingham and J. L. Maatch. 1955. The effect of starvation upon brook trout of three sizes. Progres. Fish Cult. 17:110-112.
Bilton, H. T. and G. L. Robins. 1973. The effects of starvation and subsequent feeding on survival and growth of Fulton channel sockeye salmon fry. J. Fish Res. Board Can. 30:1-5.

Chatakondi, N. G. and R. D. Yant. 2001. Application of compensatory growth to enhance production in channel catfish Ictalurus punctatus. J. World Aquac. Soc. 32:278-285.

Cho, S. H. 2005. Compensatory growth of juvenile flounder Paralichthys olivaceus L. and changes in biochemical composition and body condition indices during starvation and after refeeding during the winter season. J. World Aquac. Soc. 36:508-514.

Cho, Y. J. and S. H. Cho. 2009. Compensatory growth of olive flounder, Paralichthys olivaceus, fed the extruded pellet (EP) with different feeding regimes. J. World Aquac. Soc. 40:505512.

Cho, S. H. and T. Heo. 2011. Effect of dietary nutrient composition on compensatory growth of juvenile olive flounder Paralichthys olivaceus using different feeding regimes. Aqacult. Nutr. 17:90-97.

Cho, S. H., S. Lee, B. H. Park, S. Ji, J. Lee, J. Bae and S. Oh. 2006. Compensatory growth of juvenile olive flounder Paralichthys olivaceus $\mathrm{L}$. and changes in proximate composition and body condition indexes during fasting and after refeeding in summer season. J. World Aquac. Soc. 37:168-174.

Gaylord, T. G. and D. M. Gatlin. 2000. Assessment of compensatory growth in channel catfish Ictalurus punctatus $\mathrm{R}$. and associated changes in body condition indices. J. World Aquac. Soc. 31:326-336.

Gaylord, T. G. and D. M. Gatlin. 2001. Dietary protein and energy modifications to maximize compensatory growth of channel catfish (Ictalurus punctatus). Aquaculture 194:337-348.

Hayward, R. S., D. B. Noltie and N. Wang. 1997. Use of compensatory growth to double hybrid sunfish growth rate. Trans. Am. Fish. Soc. 126:316-322.

Hayward, R. S., N. Wang and D. B. Noltie. 2000. Group holding impedes compensatory growth of hybrid sunfish. Aquaculture 183:299-305

Heide, A., A. Foss, S. O. Stefansson, I. Mayer, B. Norberg, B. Roth, M. D. Jenssen, R.Nortvedt and A. K. Imsland. 2006. Compensatory growth and fillet crude composition in juvenile Atlantic halibut: Effects of short term starvation periods and subsequent feeding. Aquaculture 261:109-117.

Huang, G., L. Wei, X. Zhang and T. Gao. 2008. Compensatory growth of juvenile flounder Paralichthys olivaceus (Temminck \& Schelgel) following thermal manipulation. J. Fish Biol. 72:2534-2542.

Iwata, N., K. Kikuchi, H. Honda, M. Kiyono and H. Kurokura. 1994. Effects of temperature on the growth of Japanese flounder, Paralichthys olivaceus. Fish. Sci. 60:527-531.

Jobling, M., O. H. Meloy, J. Dos Santos and B. Christiansen. 1994. The compensatory growth response of the Atlantic cod: effects of nutritional history. Aquacult. Int. 2:75-90.

Jobling, M. and J. Koskela. 1996. Interindividual variations in feeding and growth in rainbow trout during restricted feeding and in a subsequent period of compensatory growth. J. Fish Biol. 49:658-667.

Kim, M. K. and R. T. Lovell. 1995. Effect of overwinter feeding regimen on body weight, body composition and resistance to Edwardsiella ictaluri in channel catfish, Ictarulus punctatus. Aquaculture 134:237-246. 
Kim, K., M. Nam, K. Kim, H. Lee, S. Hur, Y. J. Kang and M. H. Son. 2009. Effects of feeding rate and feeding frequency on growth and body composition of sub-adult flounder Paralichthys olivaceus in suboptimal water temperature. Kor. J. Fish Aqua. Sci. 42:262-267.

Kim, K., Y. J. Kang, H. M. Lee, K. Kim, M. Jang and S. Choi. 2010. Effects of dietary protein and lipid levels on growth and body composition of subadult olive flounder, Paralichthys olivaceus, at a suboptimal water temperature. J. World Aquac. Soc. 41:263-269.

Miglavs, I. and M. Jobling. 1989. The effect of feeding regime on proximate body composition and patterns of energy deposition in juvenile Arctic charr, Salvelinus alpinus. J. Fish Biol. 35:111.

Oh, S. Y., C. H. Noh and S. H. Cho. 2007. Effect of restricted feeding regimes on compensatory growth and body composition of red sea bream, Pagrus major. J. World Aquac. Soc. 38:443-449.

Quinton, J. C. and R. W. Blake. 1990. The effect of feed cycling and ration level on the compensatory growth response in rainbow trout, Oncorhynchus mykiss. J. Fish Biol. 37:33-41.
Rueda, F. M., F. J. Martinez, S. Zamora, M. Kentouri and P. Divanach. 1998. Effect of fasting and refeeding on growth and body composition of red porgy, Pagrus pagrus L. Aquacult. Res. 29:447-452

Tian, X. and J. G. Qin. 2004. Effects of previous ration restriction on compensatory growth in barramundi Lates calcarifer. Aquaculture 235:273-283.

Wang, Y., Y. Cui, Y. Yang and F. Cai. 2000. Compensatory growth in hybrid tilapia, Oreochromis mossambicus $\times$ O. niloticus, reared in seawater. Aquaculture 189:101-108.

Xie, S., X. Zhu, Y. Cui, R. J. Wootton, W. Lei and Y. Yang. 2001. Compensatory growth of the gibel carp following feed deprivation: temporal patterns in growth, nutrient deposition, feed intake and body composition. J. Fish Biol. 8:999-1009.

Zhu, X., S. Xie, Z. Zou, W. Lei, Y. Cui, Y. Yang and R. J. Wootton. 2004. Compensatory growth and food consumption in gibel carp, Carassius auratus gibelio and Chinese longsnout catfish, Leiocassis longirostris, experiencing cycles of feed deprivation and re-feeding. Aquaculture 241:235-247. 